\title{
A Test of Competing Hypotheses about Homicide Following Terrorist Attacks: An Interrupted Time Series Analysis of September 11 and Oklahoma City
}

\author{
William Alex Pridemore - Mitchell B. Chamlin · Adam Trahan
}

Published online: 9 July 2008

(C) Springer Science+Business Media, LLC 2008

\section{Erratum to: J Quant Criminol DOI 10.1007/s10940-008-9052-8}

The university affiliation of the first author, William Alex Pridemore, was incorrectly listed. It is as follows: Department of Criminal Justice, Indiana University, Sycamore Hall 302, Bloomington, IN 47405, USA, wpridemo@indiana.edu.

The online version of the original article can be found under doi:10.1007/s10940-008-9052-8.

W. A. Pridemore $(\bowtie)$

Department of Criminal Justice, Indiana University, Sycamore Hall 302, Bloomington, IN 47405, USA e-mail: wpridemo@indiana.edu

M. B. Chamlin

Division of Criminal Justice, University of Cincinnati, P.O. Box 210389, Cincinnati, OH 45221, USA

A. Trahan

Department of Criminal Justice, University of North Texas, 265 Chilton Hall, Denton, TX 76203-5130, USA 